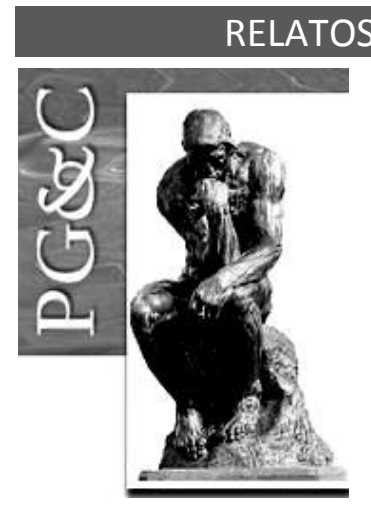

\title{
CONFIGURAÇÃO DE ESTUDOS SOBRE GESTÃO DO CONHECIMENTO EM PEQUENAS EMPRESAS NO BRASIL
}

\author{
Hilka Pelizza Vier Machado \\ Doutora em Engenharia de Produção pela Universidade Federal de Santa \\ Catarina, Brasil. Professora da Universidade do Oeste \\ de Santa Catarina, Brasil. \\ E-mail: hilkavier@yahoo.com
}

\begin{abstract}
Resumo
A gestão do conhecimento é um campo de estudos importante para pequenas empresas porque o conhecimento pode garantir a sobrevivência e o crescimento delas. O objetivo desta pesquisa é identificar a configuração de estudos sobre gestão do conhecimento em pequenas empresas no Brasil. Foi realizada uma revisão sistemática de literatura utilizando como fonte a base de dados Spell, da Associação Nacional de Programas de Pós Graduação em Administração. Foram identificados 40 estudos publicados desde 2003. A publicação sistemática passou a ocorrer a partir de 2008 e está distribuída em vinte e sete periódicos científicos. As três principais temáticas pesquisadas foram: redes, tecnologia da informação e fontes de informação. Além destas, foram identificadas outras temáticas: conhecimento em empresas familiares, informação e marketing, práticas de gestão de conhecimento por empresas de moda e gerenciamento de projetos. Com a realização desta revisão sistemática conclui-se que há ainda um campo para estudos que enfoquem principalmente o armazenamento e a reutilização de conhecimento por pequenas empresas.
\end{abstract}

Palavras-chave: Conhecimento em Pequenas Empresas. Gestão de Pequenas Empresas. Gestão do Conhecimento.

\section{CONFIGURATION OF STUDIES ABOUT KNOWLEDGE MANAGEMENT IN SMALL BUSINESS IN BRAZIL}

\begin{abstract}
The knowledge management is an important field of studies for small companies because the knowledge can help their survival and their growth. The objective of this research is to identify the configuration of studies on knowledge management in small companies in Brazil. A systematic revision of literature was developed using as source the base of data Spell, of the National Association of Programs in Administration. They were identified 40 studies published from 2003. The systematic publication started to happen from 2008 and it is distributed in twenty seven different scientific journals. The three main researched themes were: networks, technology of the information and sources of information. Besides these they were identified other themes: knowledge in family business, information and marketing, knowledge management practices in fashion enterprises and project management. With this systematic revision of literature we concluded that there is still a field of research that focus mainly the storage and reuse of knowledge for small enterprises.
\end{abstract}

Keywords: Knowledge in Small Business. Management of Small Business. Knowledge Management.

\section{INTRODUÇÃO}

Pequenas empresas têm uma participação importante nas economias, de modo que alguns países adotam políticas e estratégias para estimular o crescimento delas. Essas empresas apresentam nível elevado de inserção territorial, acompanhado de um senso de

Perspectivas em Gestão \& Conhecimento, João Pessoa, v. 8, n. 3, p. 209-227, set./dez. 2018. DOI: http://dx.doi.org/10.21714/2236-417X2018v8n3p209

http://periodicos.ufpb.br/ojs2/index.php/pgc. ISSN: 2236-417X. Publicação sob Licença (cc) EY-NC-ND 
pertencimento local da população (RINALDI, 2012; TORRÈS, 1999). No Brasil, os pequenos negócios correspondem a aproximadamente $93 \%$ dos empregos formais e apresentam um reflexo crescente em níveis de exportação (SECRETARIA DA PEQUENA EMPRESA, 2014).

Pela sua relevância, é importante que pequenas empresas cresçam. $O$ crescimento delas depende de estratégias de gestão que ampliem a gama de recursos (PENROSE, 2006). Nesse sentido, o conhecimento pode representar uma oportunidade de crescimento (SOUZA; HOLANDA; SOUSA; COSTA, 2013), na medida em que, como um recurso importante, ele pode gerar inovações e influenciar a transformação de realidades em práticas reflexivas (TSOUKAS; VLADIMIROU, 2001).

É importante que pequenas empresas adotem estratégias voltadas à gestão do conhecimento, a fim de expandir suas bases de saber (ZAHN et al., 2000). Para isso, elas precisam também monitorar o ambiente (SUTTER et al., 2013) e realizar vigilância tecnológica e de mercado, utilizando o conhecimento em diversos níveis: conhecimento de mercado, conhecimento da tecnologia e conhecimento relacional (EVANGELISTA et al., 2010). A pequena empresa que aprende incorpora a aprendizagem e o conhecimento em suas estratégias, criando uma cultura do aprendizado, compreendida por dimensões estratégicas, dos indivíduos, dos processos, da informação e da infraestrutura (JULIEN, 2013).

A pequena empresa aprendiz incorpora conhecimento e aprendizado em suas estratégias, aprimorando as formas de obtenção e de utilização da informação, possibilitando o autoquestionamento e, com isso, a empresa pode avançar mais em conhecimento, na medida em que desenvolve uma "dimensão identitária" (JULIEN, 2010, p. 139) para opor-se às forças contrárias a sua sobrevivência e desenvolvimento. Essa identidade orienta a ação do empreendimento, sendo a sua sobrevivência garantida pela forma como a empresa constantemente irá se transformar por influência da informação vinda de fora, reduzindo a entropia e tornando-se "uma processadora de conhecimento" (JULIEN, 2010, p. 141). Deste modo, o conhecimento na pequena empresa constitui um fator relevante para o crescimento e para a sobrevivência.

Disto decorre a relevância de estudos sobre conhecimento em pequenas empresas. No entanto, embora utilizada para grandes empresas, a gestão do conhecimento é pouco difundida na pequena empresa. A literatura sobre gestão do conhecimento na pequena empresa é ainda fragmentada, pouco explorada e necessita de enfoques integrados (DURST; EVARDSSON, 2012; WEE; CHUA, 2013). Considerando a importância de estudos sobre gestão do conhecimento em pequenas empresas e sendo esta um campo interdisciplinar, esta pesquisa buscou identificar, em estudos publicados no Brasil, quais foram as publicações sobre gestão do conhecimento em pequenas empresas? Este artigo é o resultado de uma revisão sistemática de literatura que teve como objetivo identificar como se configuram os estudos brasileiros sobre gestão do conhecimento em pequenas empresas, a fim de descrever tendências e lacunas.

Antes de apresentar os procedimentos metodológicos, este texto aborda alguns aspectos sobre a gestão do conhecimento e sobre gestão do conhecimento em pequenas empresas, a fim de contextualizar o tema e melhor evidenciar a escolha dos termos utilizados como busca. Na sequência, são comentados os resultados dos estudos identificados e a respectiva análise.

\section{ALGUNS ASPECTOS SOBRE A GESTÃO DO CONHECIMENTO}

A gestão do conhecimento é uma abordagem gerencial que pode ser analisada sob duas perspectivas: uma científica e outra social ou subjetiva (TZORTZAKI; MIHIOTIS, 2014; MAKAMBE, 2015). Para a perspectiva científica, o foco reside na tecnologia, na informação e

Perspectivas em Gestão \& Conhecimento, João Pessoa, v. 8, n. 3, p. 209-227, set./dez. 2018. 
no conhecimento; o conhecimento é visto como um campo ou disciplina separada e a gestão do conhecimento como um programa a ser gerido e implementado por gestores.

$\mathrm{Na}$ perspectiva social, o conhecimento é entendido como um processo, imerso também em processos informais. A compreensão subjetiva considera o conhecimento como algo que reside nas práticas e é dependente dos indivíduos, por meio de suas experiências e crenças (MAKAMBE,2015). Como uma construção coletiva, o conhecimento representa "a capacidade que os membros de uma organização possuem de estabelecer distinções na condução do trabalho, em contextos concretos específicos, por meio de generalizações resultantes do envolvimento histórico coletivo" (TSOUKAS; VLADIMIROU, 2001, p. 976). Para esta perspectiva, o conhecimento é um processo dinâmico, que propicia a transformação de uma prática não reflexiva em uma prática reflexiva, "elucidando as regras que guiam as atividades da prática, atribuindo forma particular à compreensão coletiva e facilitando o surgimento de conhecimento heurístico" (TSOUKAS; VLADIMIROU, 2001, p. 990).

$\mathrm{Na}$ perspectiva científica, o conhecimento é considerado como um programa a ser gerido e implementado. Para Dalkir (2011, p. 3), a gestão do conhecimento abrange a "geração de novos conhecimentos; o acesso a conhecimentos valiosos de fontes externas; a utilização de conhecimento acessível para tomar decisões; a inserção de conhecimento em processos, produtos e ou serviços; a representação do conhecimento em documentos, arquivos, bancos de dados, softwares; a facilitação da difusão do conhecimento por meio de cultura e incentivos; a transferência do conhecimento existente entre as diversas partes da organização e a medição do valor dos ativos de conhecimento". Nessa perspectiva, o conhecimento organizacional é gerado a partir de estágios inter-relacionados do ciclo do conhecimento, envolvendo obtenção, captura, criação, codificação, compartilhamento, armazenamento, utilização e reutilização de conhecimento. Pesquisas sobre ciclos de conhecimento resultaram em diferentes explicações e modelos, comentadas por Dalkir (2011). O modelo mais difundido é o modelo $\mathrm{SECl}$, cujo foco é a transformação do conhecimento tácito em explícito (KROGH; ICHIJO; NONAKA, 2000).

$\mathrm{Na}$ abordagem do conhecimento como programa, a origem deste encontra-se na criação ou geração do conhecimento, que é pautada em fontes variadas e atuais, sendo importante a profundidade e a credibilidade das fontes. Nesse sentido, Sordi, Cunha e Nakayama (2017) consideram que a criação do conhecimento é um processo complexo, que deriva da identificação de informações, que precisam ser conectadas para gerar conceptualização e conhecimento explícito. Outras fontes de informações para o conhecimento tácito são representadas pelos experts e especialistas, bem como por concorrentes, indivíduos e grupos. Informações e conhecimento podem ainda ter origem no aprendizado oriundo de experiências anteriores, capturado por meio de estórias organizacionais, as quais podem propiciar a oportunidade de evitar repetição de erros, assim como a oportunidade de aprendizado e de melhores práticas (DALKIR, 2011).

Após a captura, criação ou geração, o conhecimento precisa ser compartilhado, o que pode ocorrer com a adoção de Tecnologia da Informação (DALKIR, 2011; EZE et al., 2013). Pequenas empresas compartilham conhecimento entre elas, por meio de redes. $O$ compartilhamento contribui para a formação de capital social e intelectual (JULIEN, 2013; LEE; WONG, 2015).

Além do compartilhamento, o armazenamento é importante para solidificar o conhecimento explícito e para a memória organizacional. Ele pode ocorrer sob a forma física ou digital. Repositórios e intranets são mecanismos utilizados para armazenamento, como também manuais (DALKIR, 2011). O armazenamento requer atualização, dinamicidade e determinada estrutura, capaz de permitir aos indivíduos, dentre outros aspectos, relacionar conteúdos. Espera-se que o conhecimento armazenado seja utilizado e reutilizado. Utilização e

Perspectivas em Gestão \& Conhecimento, João Pessoa, v. 8, n. 3, p. 209-227, set./dez. 2018. 
reutilização do conhecimento são associadas às tecnologias de informação e comunicação (ALYA, 2012).

\subsection{Gestão do Conhecimento em Pequenas Empresas}

Para implantar a gestão do conhecimento em pequenas empresas é importante considerar a dinâmica e a estrutura dessas empresas, que difere das grandes organizações. A comunicação verbal, gestual ou visual é predominante em pequenas empresas e muitas delas conservam uma "gestão de proximidade" (TORRÈS, 1999, p. 63), proximidade do dirigente com empregados, com clientes e com fornecedores, como também proximidade entre decisões estratégicas, administrativas e operacionais. Em razão dessa proximidade, muitas dessas empresas preferem permanecer pequenas, "não desejando crescer" (JULIEN, 2010, p. 156). A proximidade é uma característica importante para o fortalecimento do pequeno negócio, juntamente com a flexibilidade e a capacidade de aprendizagem contínua (JULIEN, 2010). Ela favorece o espaço compartilhado, os encontros constantes, conversas e discussões, possibilitando a construção de laços e a troca de ideias sobre o trabalho (WEE; CHUA, 2013). Além disso, ela é importante para a produção de conhecimento heurístico, que é dependente de relações sociais e motivações (TSOUKAS; VLADIMIROU, 2001).

A proximidade e o tamanho da equipe são condições favoráveis para a aprendizagem em grupo, um requisito importante para a empresa aprendiz (JULIEN, 2013). Práticas de estórias e narrativas são favorecidas pela proximidade entre os indivíduos e são capazes de comunicar ideais complexas e multidimensionais (KÜPERS, 2005), além de propiciar a oportunidade de estórias serem contadas e recontadas de forma contextualizada. Por meio de narrativas, trabalhadores podem compartilhar experiências críticas, habilidades e know how e analisar ambiguidades, orientando a ação (GEIGER; SCHREYÖGG, 2012; GRAFTON; SELWYN, 2012). O tamanho reduzido da equipe na pequena empresa favorece o rodízio de funções e a necessidade constante de um substituir o outro no trabalho, o que pode facilitar 0 compartilhamento de conhecimento (WEE; CHUA, 2013). Para Von Krog et al. (2000) o compartilhamento do conhecimento tácito é associado à proximidade física no momento em que o trabalho está sendo realizado, requerendo observação direta, narrativas, imitações, experimentação, comparação e execução conjunta.

Ademais, pequenas empresas apresentam estrutura flexível, com poucos níveis hierárquicos e podem então serem compreendidas como "um mundo pequeno, cujo centro é o dirigente" (TORRÈS, 1999, p. 59). A pequena empresa é completamente "integrada e dependente do empreendedor, que preenche ali tarefas de direção e execução", mas a linha hierárquica "é frequentemente inexistente ou muito tênue" (JULIEN, 2010, p. 137). Os gestores são polivalentes e utilizam mais a intuição do que o planejamento formal (TORRÈS, 1999). Seus processos tendem a apresentar baixo grau de padronização e de formalização (NGUYEN, 2011).

O ambiente informal, característico da pequena empresa, influencia o conhecimento, uma vez que este reside nas práticas e é dependente dos indivíduos, por meio de suas experiências e crenças (MAKAMBE, 2015). Ele contribui para a produção de ideias, às quais estão associadas ao nível de confiança entre empregados, como também ao grau de socialização (EZE et al., 2013; WEE; CHUA, 2013). A informalidade, a proximidade e a comunicação na pequena empresa podem contribuir para o conhecimento heurístico e para o compartilhamento do conhecimento tácito (TSOUKAS; VLADIMIROU, 2001; VON KROG et al., 2000). Por outro lado, a informalidade é um fator crítico para a reutilização do conhecimento, ou para a retomada deste em uma aplicação subsequente (WEE; CHUA, 2013).

Outro traço da pequena empresa é a centralização das decisões no empreendedor, dificultando o engajamento e a confiança, necessários para propiciar a criação e o

Perspectivas em Gestão \& Conhecimento, João Pessoa, v. 8, n. 3, p. 209-227, set./dez. 2018. 
compartilhamento do conhecimento (EZE et al., 2013; WEE; CHUA, 2013). A centralização pode prejudicar o planejamento de atividades futuras e a atualização constante de informações que visam promover a circulação de informações externas e internas (JULIEN, 2010).

O conhecimento em pequenas empresas pode ser observado a partir de três pilares: recursos, fatores e processos. Os recursos são compostos por: humanos, capital e propriedade intelectual. Os fatores consistem em: cultura, liderança, infraestrutura organizacional e estratégia. No pilar processual, o conhecimento consiste em: aquisição, criação ou geração, aplicação/utilização; codificação/armazenamento e transferência/compartilhamento de conhecimento (LEE; WONG, 2015).

A criação do conhecimento abrange o gerenciamento de comunicações e a criação de um contexto adequado ao conhecimento local (CAPURRO, 2011). A aproximação com clientes é uma das estratégias utilizadas por pequenas empresas, de forma pró ativa, como fonte de informações (DESOUZA; AWAZU, 2006; WEE; CHUA, 2013). Pequenas empresas também buscam informações junto a grandes empresas, como uma fonte de conhecimento para orientar formas de ação. Um exemplo é o caso mencionado por DeSouza e Awazu (2006), de um pequeno café que se espelhava em estratégias da rede Starbucks como fonte de informações destinadas a promover o conhecimento e estratégias de gestão. Wee e Chua (2013) salientam que pequenas empresas utilizam recursos informacionais sem custos para melhorar processos e para estimular novas ideias.

A intenção de pequenas empresas em compartilhar conhecimento é dependente de atitudes associadas a cinco fatores: confiança, formalização (grau que a empresa formaliza documentos - manuais, relatórios, etc.), tecnologia do conhecimento (ênfase na tecnologia da informação), liderança encorajadora, efetivo sistema de recompensa para os empregados e motivação (EZE et al., 2013). A confiança é o principal fator que afeta o compartilhamento do conhecimento (EZE et al., 2013; WEE; CHUA, 2013). Este compartilhamento pode ocorrer na forma de comunidades de prática ((PATTINSON; PREECE, 2014). De modo geral, pequenas empresas utilizam métodos formais e informais para compartilhar conhecimento (DESOUZA; AWAZU, 2006), sendo principalmente métodos informais, por meio de conversas realizadas até mesmo em corredores da empresa (DURST; EVARDSSON, 2012). Essas empresas compartilham principalmente o conhecimento tácito, informal, com ênfase em aspectos externos, apresentando pouca fragmentação do conhecimento em relação às grandes empresas (NGUYEN, 2011).

Para armazenamento do conhecimento, pequenas empresas utilizam portais, e-mails, internet e extranet. Elas utilizam frequentemente aplicativos nas nuvens e google.docs (WEE; CHUA, 2013).

Quanto ao processo de utilização e reutilização do conhecimento por pequenas empresas, Wee e Chua (2013) mostraram que este ocorreu por meio de acessos constantes a documentos, projetos, relatórios em repositórios nas nuvens, principalmente googledocs e dropbox.

Em síntese, o conhecimento na pequena empresa é gerado a partir de fontes próximas e com baixo custo. O conhecimento compartilhado é principalmente o do tipo tácito e informal e, para o armazenamento, esse tipo de empresa utiliza preferencialmente dispositivos nas nuvens, com baixo ou nenhum custo.

\section{MÉTODO}

A fim de identificar estudos brasileiros sobre gestão do conhecimento em pequenas empresas, foi realizada uma revisão sistemática da literatura, que, segundo Hohendorff (2014), objetiva sumarizar pesquisas prévias para responder questões, testar hipóteses ou reunir evidências. A primeira etapa é a delimitação da questão a ser pesquisada, que neste caso

Perspectivas em Gestão \& Conhecimento, João Pessoa, v. 8, n. 3, p. 209-227, set./dez. 2018. 
consiste na seguinte questão: quais foram as publicações sobre gestão do conhecimento em pequenas empresas no Brasil? Revisões sistemáticas de literaturas utilizam estudos publicados como fonte de dados e seguem como método: a) definição da pergunta de pesquisa; b) identificação de fontes de dados; c) seleção de artigos, explicando critérios de inclusão e exclusão; d) seleção e síntese final dos artigos; f) resultado final (MORANDI; CAMARGO, 2015). Como fontes de dados, foram definidos artigos publicados em periódicos nacionais. A fonte de dados selecionada foi a base de dados Spell, uma base de dados da Associação Nacional de Programas de Pós-Graduação em Administração, que reúne atualmente mais de 25.000 artigos no campo da Gestão, disponível em www.spell.org.br.

Inicialmente, foi realizada uma busca, em abril de 2018, com as palavras: conhecimento em pequenas empresas; conhecimento e pequenas empresas; e gestão do conhecimento em pequenas empresas. Para os três casos o resultado da busca foi zero. Outra busca foi realizada com o termo: pequenas empresas e apareceram 320 artigos. Foi então realizada a leitura dos resumos e das palavras chaves e o critério de inclusão foi o de inserir os artigos que apresentassem no título ou em palavras chave os termos: informação, conhecimento, competências, redes, software, Tecnologia da Informação, capital intelectual. Estes termos foram extraídos da revisão da literatura. Foram identificados 44 artigos. Destes, foram extraídos da análise quatro, sendo o critério de exclusão: um deles versava sobre competências gerenciais em outro enfoque amplo, outro tratava de acesso a financiamentos bancários, um abordava cooperação entre micro e pequenas empresas, mas não com enfoque relacional e outro se referia apenas à apresentação de um software.

No total, foram lidos 40 artigos. Para análise dos dados, procurou-se identificar os temas discutidos e a relação destes com o referencial teórico apresentado na seção 2 .

\section{APRESENTAÇÃO DOS RESULTADOS}

Os primeiros estudos selecionados para esta revisão de literatura foram publicados no ano de 2003. A revisão sistematizou artigos deste período até o ano de 2017. Estes dados são mostrados no Quadro 1.

Quadro 1 - Estudos sobre Gestão do Conhecimento em Pequenas Empresas no Brasil

\begin{tabular}{|c|c|c|}
\hline $\mathbf{N}$. & Dados da Publicação & Resultados \\
\hline 1 & $\begin{array}{l}\text { PRATES, G I. A. inovação Tecnológica } \\
\text { através de sistemas de informação em } \\
\text { pequenas empresas, sucesso e desafios. } \\
\text { Revista Ciência da Administração, Fortaleza, } \\
9,1, \text { p. 42-50, } 2003 \text {. }\end{array}$ & $\begin{array}{l}\text { Investigou o uso de TI em } 25 \text { empresas } \\
\text { pequenas em Ribeirão Preto e identificou como } \\
\text { resistências dos funcionários a implantação e, } \\
\text { como vantagens, o aumento da capacidade de } \\
\text { trabalho e aumento de competitividade das } \\
\text { empresas. }\end{array}$ \\
\hline 2 & $\begin{array}{l}\text { ALMEIDA, D. M.; CORDEIRO, M. B. O uso da } \\
\text { informação e da pesquisa de marketing } \\
\text { como fator de sucesso na atuação das micro } \\
\text { e pequenas empresas, CRCSL \& Você, } \\
\text { Florianópolis, 3, 6, p. 45-53, 2003. }\end{array}$ & $\begin{array}{l}\text { Discussão teórica sobre a importância da } \\
\text { informação para o marketing e para a pesquisa } \\
\text { de marketing. }\end{array}$ \\
\hline 3 & $\begin{array}{l}\text { PRATES, G. A., OSPINA, M. T. Tecnologia da } \\
\text { informação em pequenas empresas: fatores } \\
\text { de êxito, restrições e benefícios. Revista de } \\
\text { Administração contemporânea, 8, 2, p. 9- } \\
26,2004 \text {. }\end{array}$ & $\begin{array}{l}\text { Estudo com } 25 \text { empresas. Os resultados } \\
\text { mostraram que a implantação da TI possibilitou } \\
\text { percepção da necessidade pelos usuários e } \\
\text { apoio da cúpula. Como benefícios, a melhoria } \\
\text { na compreensão produtiva e aumento na } \\
\text { satisfação dos usuários. }\end{array}$ \\
\hline 4 & $\begin{array}{l}\text { NETTO, A.V., VALERIO, D. M. Gestão de } \\
\text { Pessoas altamente qualificadas em }\end{array}$ & $\begin{array}{l}\text { Os autores sugerem estratégias para pequenas } \\
\text { empresas de base tecnológica buscarem }\end{array}$ \\
\hline
\end{tabular}

Perspectivas em Gestão \& Conhecimento, João Pessoa, v. 8, n. 3, p. 209-227, set./dez. 2018. 


\begin{tabular}{|c|c|c|}
\hline & $\begin{array}{l}\text { pequenas empresas de base tecnológica. } \\
\text { Revista de Administração da Mackenzie, } \\
\text { 7,3, p. 131-147, 2006. }\end{array}$ & profissionais qualificados, mestres e doutores. \\
\hline 5 & $\begin{array}{l}\text { FEDRIZZI, L. B., ROLDAN, L. B., LENZ, G. S., } \\
\text { HANSEN, P. B. Redes horizontais de } \\
\text { cooperação contribuindo para o processo } \\
\text { de inovação em micro e pequenas empresas } \\
\text { brasileiras. Revista de Administração da } \\
\text { UNIMEP, 6, 3, p. 1-23, 2008. }\end{array}$ & $\begin{array}{l}\text { Os resultados mostraram que redes horizontais } \\
\text { propiciaram novos sistemas de compras e } \\
\text { marketing em conjunto nas redes que } \\
\text { analisaram, em Porto Alegre. }\end{array}$ \\
\hline 6 & $\begin{array}{l}\text { CASSANDRE, M. P., ENDRICI, J. M., VERCESI, } \\
\text { C. Gestão por competências nas pequenas } \\
\text { empresas do arranjo produtivo local de } \\
\text { bonés da cidade de Apucarana (PR): seu } \\
\text { entendimento e suas práticas em confronto } \\
\text { com as perspectivas teóricas. Revista de } \\
\text { Administração da Mackenzie, 9,8, p. } 1-24 \text {, } \\
2008 \text {. }\end{array}$ & $\begin{array}{l}\text { O estudo procurou identificar a compreensão } \\
\text { da gestão por competências em pequenas } \\
\text { empresas, no Estado do Paraná. Os autores } \\
\text { identificaram que o conceito Gestão por } \\
\text { competência era pouco conhecido dos } \\
\text { empresários. }\end{array}$ \\
\hline 7 & $\begin{array}{l}\text { BRITO, A. G. C., ESCRIVÃO FILHO, E. Gestão } \\
\text { Estratégica da informação: análise e } \\
\text { propostas de melhorias às pequenas } \\
\text { empresas do setor de serviços. Revista da } \\
\text { Micro e Pequena Empresa da Faculdade } \\
\text { Campo Limpo Paulista, 3,2, p. 91-105, } 2009 .\end{array}$ & $\begin{array}{l}\text { Os resultados do estudo mostraram que as } \\
\text { fontes informais subsidiam as decisões } \\
\text { tomadas e que a informação é centralizada. }\end{array}$ \\
\hline 8 & $\begin{array}{l}\text { GALLON, A. V., ENSSLIN, S. R., SILVEIRA, A. } \\
\text { Rede de relacionamentos em pequenas } \\
\text { empresas de base tecnológica (EBTs) } \\
\text { incubadas: um estudo da importância para } \\
\text { o desempenho organizacional na percepção } \\
\text { de empreendedores. Revista de Gestão de } \\
\text { Tecnologia e Sistemas de Informação, 6, 3, } \\
\text { p. 551-572, } 2009 \text {. }\end{array}$ & $\begin{array}{l}\text { Estudo com } 14 \text { pequenas empresas de base } \\
\text { tecnológica incubadas, mostrando o efeito } \\
\text { positivo da rede sobre o desempenho. }\end{array}$ \\
\hline 9 & $\begin{array}{l}\text { CANCELLIER, E L. P., ALBERTON, A., DA } \\
\text { SILVA, A.B., MARCON, R. O monitoramento } \\
\text { de informações estratégicas do ambiente } \\
\text { externo em pequenas empresas. Revista } \\
\text { Ibero-americana de Estratégia, 8,1, p. 28- } \\
51,2009 \text {. }\end{array}$ & $\begin{array}{l}\text { Estudo com } 83 \text { empresas. Os autores } \\
\text { constataram o número reduzido de fontes de } \\
\text { informações utilizadas por elas, sendo a maior } \\
\text { barreira o perfil gerencial do dirigente. A } \\
\text { necessidade de clientes foi o aspecto mais } \\
\text { monitorado e as fontes mais utilizadas foram: } \\
\text { contato direto com clientes, jornais e revistas, } \\
\text { contato com fornecedores e feiras e } \\
\text { exposições. }\end{array}$ \\
\hline 10 & $\begin{array}{l}\text { DALFOVO, O., SHARF, E. R. \& KRAMBECK, G. } \\
\text { A Gestão do conhecimento em ambientes } \\
\text { intensivos de conhecimento: as Pequenas } \\
\text { Empresas Incubadas de Software. Journal of } \\
\text { Information Systems and Technology } \\
\text { Management, 6, 1, p. 45-60, } 2009 \text {. }\end{array}$ & $\begin{array}{l}\text { Estudo realizado junto a } 26 \text { empresas pequenas } \\
\text { de software. }\end{array}$ \\
\hline 11 & $\begin{array}{l}\text { WENGER, D., MISOCSKY, M.C. Avaliação de } \\
\text { Desempenho de redes de pequenas } \\
\text { empresas: contribuições da abordagem da } \\
\text { produção do sentido. Organização \& } \\
\text { Sociedade, } 17,53, \text { p. } 345-361,2010 .\end{array}$ & $\begin{array}{l}\text { Apresentação de modelo para construção de } \\
\text { sentidos por empreendedores, a partir da } \\
\text { inserção em redes inter organizacionais. }\end{array}$ \\
\hline 12 & $\begin{array}{l}\text { LUNARDI, G..L., DOLCl, P. C., MAÇADA, } \\
\text { A.C.G. Adoção de tecnologia de informação } \\
\text { e seu impacto no desempenho }\end{array}$ & $\begin{array}{l}\text { Estudo realizado junto a } 123 \text { empresas, } \\
\text { constatando que elas adotaram TI por pressões } \\
\text { externas de concorrentes, fornecedores e }\end{array}$ \\
\hline
\end{tabular}

Perspectivas em Gestão \& Conhecimento, João Pessoa, v. 8, n. 3, p. 209-227, set./dez. 2018. 


\begin{tabular}{|c|c|c|}
\hline & $\begin{array}{l}\text { organizacional: um estudo realizado com } \\
\text { micro e pequenas empresas. Revista de } \\
\text { Administração, 45, 1, p. 05-17, } 2010 \text {. }\end{array}$ & governo. \\
\hline 13 & $\begin{array}{l}\text { ROSSONI, C. F. Balance Scorecard mediado } \\
\text { pela Gestão de Conhecimento: modelo de } \\
\text { uso para micro e pequenas empresas. } \\
\text { Revista da Micro e Pequena Empresa da } \\
\text { Faculdade Campo Limpo Paulista, 3,3, p. 20- } \\
\text { 35, } 2010 \text {. }\end{array}$ & $\begin{array}{l}\text { Os autores sugerem um modelo de gestão } \\
\text { baseado no Balance Scorecard para ser } \\
\text { utilizado por micro e pequenas empresas. }\end{array}$ \\
\hline 14 & $\begin{array}{l}\text { BERNARDES, D. P. G., MIRANDA, L. C. } \\
\text { Quatro Histórias da utilização de } \\
\text { informação econômico financeira nas MPES: } \\
\text { lições para futuros empreendedores. } \\
\text { Revista de Micro e Pequena Empresa, 5, 3, } \\
\text { p. 84-98, } 2011 .\end{array}$ & $\begin{array}{l}\text { Estudo realizado junto a quatro empresas. Os } \\
\text { resultados mostraram baixo reconhecimento } \\
\text { da importância da informação econômico- } \\
\text { financeira. }\end{array}$ \\
\hline 15 & $\begin{array}{l}\text { SANT'ANNA, P. R., LONGO, O. C., BARONE, } \\
\text { F. M., COVA, C. J. G., OLIVEIRA, F. A. } \\
\text { Tecnologia da Informação como ferramenta } \\
\text { para análise econômico financeira. Revista } \\
\text { de Administração Pública, } 45,5 \text {, p. 1589- } \\
1611,2011 .\end{array}$ & $\begin{array}{l}\text { Discussão teórica sobre a relevância de } \\
\text { integração de sistemas de informações } \\
\text { contábeis e gerenciais. }\end{array}$ \\
\hline 16 & $\begin{array}{l}\text { CANCELLIER, E.L.P.L., SALUM, A.R.C. } \\
\text { Monitoramento do ambiente e } \\
\text { desempenho em pequenas empresas. } \\
\text { Revista de Administração da Inovação, 8, 3, } \\
\text { p. 55-77, 2011. }\end{array}$ & $\begin{array}{l}\text { Pesquisa realizada junto a } 92 \text { empresas em } \\
\text { Santa Catarina, apontando relação positiva } \\
\text { entre práticas de monitoramento e } \\
\text { desempenho de empresas. Ênfase das } \\
\text { empresas em informações de clientes e de } \\
\text { fornecedores, mais do que em aspectos do } \\
\text { ambiente geral, exceto para o caso de clientes. }\end{array}$ \\
\hline 17 & $\begin{array}{l}\text { MAHELER, A. E D. ; VENTURINI, J. C. Criação } \\
\text { e disseminação de conhecimento local em } \\
\text { pequenas empresas familiares: o caso de } \\
\text { cantinas de vinho da região da quarta } \\
\text { colônia de imigração italiana, no Rio Grande } \\
\text { do Sul. Revista lbero-Americana de } \\
\text { Estratégia, 10, 2, p. 181-207, 2011. }\end{array}$ & $\begin{array}{l}\text { Estudo com empresas familiares, que apontou } \\
\text { que o conhecimento tácito é transmitido entre } \\
\text { gerações e que há um desinteresse de } \\
\text { sucessores pelo conhecimento acumulado. }\end{array}$ \\
\hline 18 & $\begin{array}{l}\text { CARVALHO, L. F. Gestão da Informação em } \\
\text { micro e pequenas empresas: um estudo do } \\
\text { APL do vestuário de Jaraguá, Goiás. } \\
\text { Perspectivas em Gestão \& Conhecimento, 2, } \\
\text { p. 57-72, 2012. }\end{array}$ & $\begin{array}{l}\text { Entre as empresas pesquisadas, os autores } \\
\text { constataram que elas nunca utilizavam } \\
\text { informações de universidade e de institutos de } \\
\text { pesquisa e que sempre utilizavam jornais e } \\
\text { revistas eletrônicas. As principais fontes foram: } \\
\text { Feiras e Eventos, seguida de outras empresas } \\
\text { do setor e do SEBRAE. As menos utilizadas } \\
\text { foram publicações governamentais. }\end{array}$ \\
\hline 19 & $\begin{array}{l}\text { GOIS, P. H, MACHADO, H. P. V. Uma } \\
\text { abordagem sobre o papel das redes para } \\
\text { pequenas empresas e sobre os efeitos no } \\
\text { aprendizado de empreendedores. Revista } \\
\text { de Empreendedorismo e Gestão de } \\
\text { Pequenas Empresas, } 1,1, \text { p. } 1-21,2012 .\end{array}$ & $\begin{array}{l}\text { Discussão teórica sobre a importância das } \\
\text { redes como mecanismo de formação de } \\
\text { competência de empreendedores. }\end{array}$ \\
\hline 20 & $\begin{array}{l}\text { ZAMPIERI, M.A., TAKAHASHI, A.R.W. } \\
\text { Aprendizagem e Competências } \\
\text { Empreendedoras: estudo de casos de MPE } \\
\text { do setor educacional. Revista Gestão } \\
\text { Organizacional, 6, 4, p. 3-18, 2013. }\end{array}$ & $\begin{array}{l}\text { Estudo multi caso com nove casos do setor } \\
\text { educacional, evidenciando a importância da } \\
\text { experiência como fonte de aprendizado, sendo } \\
\text { Explotation o modo predominante de } \\
\text { transformar experiência em conhecimento. }\end{array}$ \\
\hline
\end{tabular}

Perspectivas em Gestão \& Conhecimento, João Pessoa, v. 8, n. 3, p. 209-227, set./dez. 2018. 


\begin{tabular}{|c|c|c|}
\hline 21 & $\begin{array}{l}\text { SOUZA, D, L., ZAMBADI, A. L., OLIVEIRA, N. } \\
\text { Estratégia de Criação de Conhecimento em } \\
\text { MPEs por meio de Programas de Estágio: } \\
\text { uma realidade ou um desafio? Revista de } \\
\text { Empreendedorismo e Gestão de Pequenas } \\
\text { Empresas, } 2,3, \text { p. 33-56, } 2013 \text {. }\end{array}$ & $\begin{array}{l}\text { Estudo realizado em Minas Gerais com } 14 \\
\text { empresários e } 33 \text { estagiários, abordando a } \\
\text { criação de conhecimento em estágio. }\end{array}$ \\
\hline 22 & $\begin{array}{l}\text { SILVEIRA, M. A. P., AZEVEDO, R. R. A } \\
\text { contribuição dos relacionamentos inter } \\
\text { organizacionais no processo de } \\
\text { aprendizagem em gestão empresarial: um } \\
\text { estudo em MPES no Polo Design Center. } \\
\text { Revista da Pequena Empresa da FACCAMP, } \\
\text { 8,1, p. 68-83, 2014. }\end{array}$ & $\begin{array}{l}\text { Resultados da pesquisa mostraram que a rede } \\
\text { apresentou baixa contribuição para o } \\
\text { aprendizado de gestores e que as fontes mais } \\
\text { efetivas de conhecimento e aprendizado foram } \\
\text { os consultores e cursos. }\end{array}$ \\
\hline 23 & $\begin{array}{l}\text { SILVA, W. A., TEIXEIRA, R. M. Adoção da } \\
\text { Tecnologia da Informação pelas MPEs no } \\
\text { setor hoteleiro de Sergipe. Revista Brasileira } \\
\text { de Pesquisa em Turismo. 8, 1, p. 59-77, } \\
2014 \text {. }\end{array}$ & $\begin{array}{l}\text { Pesquisa exploratória sobre a adoção da } \\
\text { Tecnologia da Informação em hotéis em } \\
\text { Sergipe. }\end{array}$ \\
\hline 24 & $\begin{array}{l}\text { MARTENS, C. D. P., BELFORT, A. C., } \\
\text { CARNEIRO, K.D.A., MARTENS, M.B. } \\
\text { Gerenciamento de Projetos em MPEs. } \\
\text { Revista Pensamento Contemporâneo em } \\
\text { Administração, 8, 3, p. 151-171, } 2014 .\end{array}$ & $\begin{array}{l}\text { Survey realizada com } 54 \text { empresas, mostrando } \\
\text { a influência do empreendedor no } \\
\text { gerenciamento de projetos. }\end{array}$ \\
\hline 25 & $\begin{array}{l}\text { CARLOS FILHO, F. A., LAGIOIA, V.C.T., } \\
\text { MONTEIRO, J.A.M., SILVA FILHO, L.L., DE } \\
\text { ARAUJO, J. G., ARAUJO, J. G. N. Importância } \\
\text { e Contribuição do Ativo intangível: } \\
\text { percepção dos empreendedores de MPEs } \\
\text { sobre o capital intelectual. Organizações em } \\
\text { Contexto, 10, 20, p. 1-27, 2014.. }\end{array}$ & $\begin{array}{l}\text { Pesquisa realizada junto a } 84 \text { empreendedores, } \\
\text { sendo que a metade não conhecia o termo } \\
\text { ativo intangível, mas a metade avaliou como } \\
\text { importante o papel de funcionários para a } \\
\text { competitividade da empresa. }\end{array}$ \\
\hline 26 & $\begin{array}{l}\text { SOUZA, G. H. S., LIMA, N. C., COELHO, J. A. } \\
\text { P., OLIVEIRA, S. V. W., MILITO, C. N. A } \\
\text { influência das redes de cooperação no } \\
\text { desenvolvimento } \\
\text { Desenvolvimento em Questão, 13, 31, p. } \\
\text { 259-294, } 2015 .\end{array}$ & $\begin{array}{l}\text { Estudo realizado em Alagoas, com empresas de } \\
\text { software, mostrando efeitos das redes sobre a } \\
\text { geração de cursos e capacitações para aumento } \\
\text { do capital intelectual das empresas. }\end{array}$ \\
\hline 27 & $\begin{array}{l}\text { BARBOZA, R. A. B., FONSECA, G. A, } \\
\text { RAMALHEIRO, G. C. F. Inovação em MPEs } \\
\text { por meio do Serviço Brasileiro de Respostas } \\
\text { técnicas. Revista de Administração da } \\
\text { Inovação, 12, 3, p. 330-349, } 2015 .\end{array}$ & $\begin{array}{l}\text { Análise da utilização do serviço de Respostas } \\
\text { técnicas por empresas a partir dos registros do } \\
\text { sistema. }\end{array}$ \\
\hline 28 & $\begin{array}{l}\text { DESIDÉRIO, P. H. M.; POPADIUK, S. Redes de } \\
\text { inovação aberta e compartilhamento de } \\
\text { conhecimento: aplicações em pequenas } \\
\text { empresas. } \\
\text { da Inovista de Administração } \\
\end{array}$ & $\begin{array}{l}\text { Os autores apresentam como um dos } \\
\text { resultados o aprendizado no ambiente } \\
\text { interativo por meio da absorção tecnológica. }\end{array}$ \\
\hline 29 & $\begin{array}{l}\text { LÖBLER, M. L., VISENTINI, M. S., LEHNHART, } \\
\text { E. R., KEIMECK, A. Elaboração de } \\
\text { instrumentos para mensurar os fatores } \\
\text { influenciadores na aquisição e na } \\
\text { implantação de Sistemas de Informação em } \\
\text { micro e pequenas empresas. Revista de } \\
\text { Administração, Contabilidade e Economia } \\
\text { da FUNDACE, 6,1, p. 2-18, } 2015 \text {. }\end{array}$ & $\begin{array}{l}\text { Proposta de instrumentos para mensuração de } \\
\text { aquisição e implantação de sistemas de } \\
\text { informação. }\end{array}$ \\
\hline
\end{tabular}

Perspectivas em Gestão \& Conhecimento, João Pessoa, v. 8, n. 3, p. 209-227, set./dez. 2018. 


\begin{tabular}{|c|c|c|}
\hline 30 & $\begin{array}{l}\text { WEGNER, D., BORTOLASO, I. V., ZANATTO, } \\
\text { P.A.F. Redes de pequenas empresas e } \\
\text { estratégias de consolidação: evidências do } \\
\text { contexto brasileiro. Revista brasileira de } \\
\text { Gestão de Negócios, 18, 62, p. 525-544, } \\
2016 \text {. }\end{array}$ & $\begin{array}{l}\text { Estudo de caso com três empresas de } \\
\text { diferentes setores, mostrando a composição } \\
\text { das redes das empresas. }\end{array}$ \\
\hline 31 & $\begin{array}{l}\text { FINARDI, C., DA SILVA, E. L., RADOS, G. J. V. } \\
\text { O fluxo da informação em processo de } \\
\text { design de moda: uma análise aplicada em } \\
\text { pequenas empresas e confecção da grande } \\
\text { Florianópolis. Perspectivas em Gestão \& } \\
\text { Conhecimento, 6, 2, p. 204-217, } 2016 .\end{array}$ & $\begin{array}{l}\text { Os autores identificaram as principais fontes } \\
\text { utilizadas pelas e empresas de moda: sites da } \\
\text { internet, revistas especializadas e catálogos de } \\
\text { fornecedores. Constataram que o fluxo de } \\
\text { comunicação era predominantemente } \\
\text { informal. }\end{array}$ \\
\hline 32 & $\begin{array}{l}\text { MENEZES, O. R. C., OLAVE, M. E. Práticas de } \\
\text { Gestão de Conhecimento em Micro e } \\
\text { Pequenas Empresas de Sergipe. Gestão \& } \\
\text { Regionalidade, 32, 94, } 2016 \text {. }\end{array}$ & $\begin{array}{l}\text { Estudo realizado junto a cinco empresas de } \\
\text { confecção. Como práticas de GC as empresas } \\
\text { utilizavam: conversas com clientes, } \\
\text { representantes, fornecedores e concorrentes; } \\
\text { reuniões com outras empresas; participação } \\
\text { em cursos e treinamentos e monitoramento de } \\
\text { mercado. }\end{array}$ \\
\hline 33 & $\begin{array}{l}\text { VERSCHOORE, J. R., KLANOVICS, C., } \\
\text { DURAYSKI, J., VIEIRA, L. Como a gestão das } \\
\text { redes estratégicas regionais afeta os ganhos } \\
\text { proporcionados às pequenas empresas } \\
\text { associadas. Gestão \& Regionalidade, 32, 94, } \\
\text { p. 131-147, 2016. }\end{array}$ & $\begin{array}{l}\text { Pesquisa realizada junto a } 150 \text { empresas } \\
\text { apontando efeitos da aprendizagem em redes. }\end{array}$ \\
\hline 34 & $\begin{array}{l}\text { OLIVEIRA, D. L., LIPKE, F. A.; SILVA, S. R. F. } \\
\text { Capacidades de internet Banking e } \\
\text { Desempenho das Pequenas Empresas: o } \\
\text { valor do negócio da TI na perspectiva de } \\
\text { capacidades externas. BASE-Revista de } \\
\text { Administração e Contabilidade da } \\
\text { UNISINOS, 13,4, p. 265-278, out-dez 2016. }\end{array}$ & $\begin{array}{l}\text { A pesquisa teve como objetivo identificar a } \\
\text { relação entre capacidades de internet banking } \\
\text { e desempenho de pequenas empresas nos } \\
\text { níveis de processo e de empresa. Os resultados } \\
\text { mostraram impacto direto no desempenho de } \\
\text { processos. Os autores não observaram impacto } \\
\text { direto sobre o desempenho da empresa. }\end{array}$ \\
\hline 35 & $\begin{array}{l}\text { SPERAFICO, J. H.; ENGELMAN, R.; } \\
\text { GONÇALVES, M. A. Capital intelectual } \\
\text { organizacional e inovação em Micro e } \\
\text { Pequenas Empresas de Base Tecnológica. } \\
\text { RAUnP- Revista Eletrônica do Mestrado } \\
\text { Profissional em Administração da } \\
\text { Universidade Potiguar, 9, 1, p. 51-61, junho- } \\
\text { nov 2016. }\end{array}$ & $\begin{array}{l}\text { Estudaram a relação entre capital intelectual e } \\
\text { inovação em pequenas empresas de base } \\
\text { tecnológica. Estudo mostrou que o capital } \\
\text { intelectual exerceu efeito favorável sobre a } \\
\text { inovação, mas que a estratégia de inovação } \\
\text { também foi importante. }\end{array}$ \\
\hline 36 & $\begin{array}{l}\text { KRAKAUER, P. V. C.; ALMEIDA, M. I. R. O uso } \\
\text { da informação do ambiente no processo de } \\
\text { decisão estratégica de empresários } \\
\text { brasileiros e americanos de pequenas } \\
\text { empresas. BASE-Revista de Administração e } \\
\text { Contabilidade da UNISINOS, 13,2, p. 111- } \\
\text { 121, abr-jun } 2016 \text {. }\end{array}$ & $\begin{array}{l}\text { Estudo comparativo sobre práticas para o uso } \\
\text { de informação externa no processo decisório } \\
\text { estratégico por pequenas empresas brasileiras } \\
\text { e americanas. Diferenças encontradas foram } \\
\text { associadas ao uso da intuição e de } \\
\text { compartilhamento de informação com } \\
\text { familiares, especialmente para os casos } \\
\text { brasileiros e, disseminação da informação com } \\
\text { equipe de trabalho. Os autores destacam a } \\
\text { forma informal e assimétrica de busca de } \\
\text { informação externa para os casos analisados. }\end{array}$ \\
\hline 37 & $\begin{array}{l}\text { JORDÃO, R. V. D. Práticas de Gestão do } \\
\text { conhecimento na internacionalização de } \\
\text { pequenas empresas: um estudo }\end{array}$ & $\begin{array}{l}\text { No estudo, os autores identificaram que a } \\
\text { criação, manutenção e compartilhamento do } \\
\text { conhecimento e da informação são }\end{array}$ \\
\hline
\end{tabular}

Perspectivas em Gestão \& Conhecimento, João Pessoa, v. 8, n. 3, p. 209-227, set./dez. 2018. 


\begin{tabular}{|c|c|c|}
\hline & $\begin{array}{l}\text { comparativo de casos na indústria de café. } \\
\text { BASE-Revista de Administração e } \\
\text { Contabilidade da UNISINOS, 13, 2, p. 171- } \\
\text { 186, abr-jun } 2016 .\end{array}$ & $\begin{array}{l}\text { influenciados pela rede, pela cultura, pela } \\
\text { cooperação e por interações entre as } \\
\text { empresas. A rede representou um contexto } \\
\text { favorável }(\mathrm{Ba}) \text { para criação de conhecimento e } \\
\text { de habilidades para indivíduos e empresas. }\end{array}$ \\
\hline 38 & $\begin{array}{l}\text { LUNARDI, G. L.; DOLCI, D. B. Adoção de } \\
\text { Tecnologia da informação e sua relação com } \\
\text { a gestão de negócios em micro e pequenas } \\
\text { empresas. Revista de Administração da } \\
\text { UFSM, 10,5, p. 929-948, dez } 2017 \text {. }\end{array}$ & $\begin{array}{l}\text { A pesquisa abordou a adoção de Tecnologia da } \\
\text { Informação em PMEs em relação às atividades } \\
\text { administrativas. Eles avaliaram dez dimensões } \\
\text { de atividades associadas a pessoas, caixa, } \\
\text { ponto de vendas, gestão de suprimentos, } \\
\text { crédito, qualidade, planejamento e clientes. Os } \\
\text { resultados mostraram que as empresas que } \\
\text { utilizaram tecnologia de informação foram as } \\
\text { que mais adotaram as práticas de gestão } \\
\text { analisadas. }\end{array}$ \\
\hline 39 & $\begin{array}{l}\text { BENEDETTI, M. H.; GHOBRIL, N.; } \\
\text { ALBARELLO, E. B. Possíveis interações entre } \\
\text { conhecimentos externos e internos nos } \\
\text { processos de inovações de micro e } \\
\text { pequenas empresas. Revista Capital } \\
\text { científico-eletrônica, 15,3, p. 90-110, } 2017 .\end{array}$ & $\begin{array}{l}\text { Os pesquisadores investigaram práticas de } \\
\text { gestão da inovação em PMEs voltadas a captar } \\
\text { e absorver conhecimentos de fontes externas. } \\
\text { Como fontes externas de informações } \\
\text { utilizadas pelas empresas eles identificaram: } \\
\text { clientes, Feiras, encontros, congressos, } \\
\text { reuniões, redes, palestras, treinamentos e } \\
\text { contato com fornecedores. Para } \\
\text { compartilhamento de conhecimento as } \\
\text { empresas utilizaram conversas informais e } \\
\text { trocas de experiências. }\end{array}$ \\
\hline 40 & $\begin{array}{l}\text { SOUZA, E. M. O.; OLIVEIRA, D. L.; CUSTÓDIO, } \\
\text { E. M. O. Efeitos e características da } \\
\text { consumrerização de TI nas micro e } \\
\text { pequenas empresas: um estudo } \\
\text { exploratório. Amazônia. Organizações e } \\
\text { Sustentabilidade, 6, 1, p. 179-195, jan./jun. } \\
2017 .\end{array}$ & $\begin{array}{l}\text { A pesquisa destacou benefícios, apontados } \\
\text { pelas empresas e pelos empregados, } \\
\text { associados ao uso de TI que foram: rapidez de } \\
\text { adaptação a mudanças tecnológicas e } \\
\text { disponibilidade do empregado fora do } \\
\text { expediente. O telefone celular foi o recurso } \\
\text { tecnológico mais utilizado. }\end{array}$ \\
\hline
\end{tabular}

Fonte: Dados da pesquisa 2018 (Disponível em: www.spell.org.br)

De acordo com os dados do Quadro 1, foi a partir do ano 2008 que os estudos passaram a ser publicados de forma mais sistemática. O número máximo de artigos publicados por ano até o ano de 2015 foi quatro. Em 2016 foram publicados oito artigos e, em 2017, três artigos. Quanto às fontes de publicação, observa-se na Tabela 1 que a produção foi distribuída em vinte e sete periódicos científicos, evidenciando o caráter multidisciplinar e interdisciplinar do campo.

Tabela 1 - Número de artigos publicados por Periódico Científico

\begin{tabular}{l|c}
\hline Nome da Revista & $\begin{array}{l}\text { Número de } \\
\text { artigos } \\
\text { publicados }\end{array}$ \\
\hline Revista de Ciências Administrativas & 1 \\
\hline CRCSL & 1 \\
\hline Revista de Administração Contemporânea & 1 \\
\hline Revista de Administração da Mackenzie & 2 \\
\hline Revista de Administração da UNIMEP & 1 \\
\hline Perspectivas em Gestão \& Conhecimento & 2 \\
\hline Revista de Empreendedorismo e Gestão de Pequenas Empresas & 2 \\
\hline
\end{tabular}

Perspectivas em Gestão \& Conhecimento, João Pessoa, v. 8, n. 3, p. 209-227, set./dez. 2018. 


\begin{tabular}{l|l}
\hline Revista de Micro e Pequena Empresa & 4 \\
\hline Revista de Administração Pública & 1 \\
\hline Revista de Administração da Inovação & 3 \\
\hline Revista Ibero Americana de Estratégia & 2 \\
\hline Organização \& Sociedade & 1 \\
\hline Revista de Administração & 1 \\
\hline Revista de Gestão de Tecnologia e Sistema de Informação & 2 \\
\hline Revista Brasileira de Turismo & 1 \\
\hline Revista Gestão Organizacional & 1 \\
\hline Organizações em Contexto & 1 \\
\hline Pensamento Contemporâneo em Administração & 1 \\
\hline Gestão \& Regionalidade & 2 \\
\hline Desenvolvimento em Questão & 1 \\
\hline Revista de Administração e Contabilidade da FUNDACE & 1 \\
\hline Revista Brasileira de Gestão de Negócios & 1 \\
\hline Revista de Administração da Universidade Federal de Santa Maria & 1 \\
\hline Revista Capital científico Eletrônica & 1 \\
\hline Amazônia, Organizações e Sustentabilidade & 1 \\
\hline BASE - Revista de Administração e Contabilidade da UNISINOS & 3 \\
\hline Revista Eletrônica do Mestrado Profissional em Administração da Universidade & 1 \\
\hline Potiguar & \\
\hline Fonte: Dados da Pesquisa (2017) & \\
\hline
\end{tabular}

Fonte: Dados da Pesquisa (2017)

Os periódicos que mais publicaram sobre o tema foram: Revista de Micro e Pequena Empresa, Revista de Administração da Inovação e BASE-Revista de Administração e Contabilidade da UNISINOS. Com dois artigos publicados estão os periódicos: Revista de Administração da Mackenzie, Perspectivas em Gestão \& Conhecimento, Revista de Empreendedorismo e Gestão de Pequenas Empresas, Revista Ibero Americana de Estratégia, Revista de Gestão de Tecnologia e Sistema de Informação, Revista Gestão \& Regionalidade e Revista Brasileira de Gestão de Negócios.

Quanto aos interesses de pesquisa, a principal temática, em termos de número de pesquisas e artigos, foi sobre redes inter organizacionais. Em geral, os estudos enfatizaram as redes como mecanismos de geração, partilha do conhecimento e como contribuição para o capital social das empresas (DESIDÉRIO; POPADIUK, 2015; FEDRIZZI et al., 2008; GOIS; MACHADO, 2012; JORDÃO, 2016; WENGER; MISOCSKY, 2010; GALLON et al., 2009; SILVEIRA; AZEVEDO, 2014; SOUZA et al., 2015; WEGNER et al., 2016; VERSCHOORE et al., 2016).

Outra temática pesquisada foi sobre a adoção de TI por pequenas empresas (OLIVEIRA et al., 2016; PRATES, 2003; PRATES, 2004; SANT'ANNA et al., 2011; LUNARDI et al.., 2010; SILVA, TEIXEIRA, 2014; SOUZA et al. 2016). Os resultados não são conclusivos sobre os efeitos da utilização de $\mathrm{TI}$ sobre desempenho das empresas.

A terceira temática mais pesquisada foi sobre fontes de informações. Esta foi objeto de estudo para pesquisas realizadas por Brito e Escrivão Filho (2009); Carvalho (2012); Cancellier et al. (2011); Cancellier et al. (2009), Finardi et al. (2016), Benedetti et al. (2016). Como fontes de informações externas, os resultados dos estudos analisados corroboram resultados de outros estudos, como DeSouza e Awazu (2006) e Wee e Chua (2013), no que se refere à obtenção de informação por clientes. Recentemente Taghizadeh, Rahman e Hossain (2018) destacaram três dimensões do conhecimento associadas aos clientes: conhecimento a partir do consumidor, conhecimento para o consumidor e conhecimento sobre o consumidor. Nesse sentido, estudos futuros podem explorar dimensões associadas a esta fonte de informação. Além disso, entre as práticas de gestão de conhecimento voltadas à criação do conhecimento alguns aspectos não foram identificados nos estudos analisados, como, por exemplo, a 
utilização de técnicas criativas e de trabalhos colaborativos, aos quais se referem Menezes, Johann, Valentim e Scott (2017).

Além destes três principais temas, outros temas identificados nas pesquisas foram: conhecimento em empresas familiares (MAHELER; VENTURINI, 2011); informação e marketing (ALMEIDA; CORDEIRO, 2003); pesquisa sobre conhecimento e gestão por competências e ativo intangível (CARLOS FILHO et al., 2014; CASSANDRE et al., 2008), práticas de gestão do conhecimento por empresas de moda (MENEZES; OLAVE, 2016), gerenciamento de projetos (MARTENS et al., 2014) e modelos para desempenho, competências e redes (ZAMPIERI; TAKAHASHI, 2013; WENGER; MISOCSKY, 2010).

Nota-se que a ênfase dos estudos publicados encontra-se na criação e no compartilhamento do conhecimento. $O$ enfoque predominante foi sobre a informação e a infraestrutura (JULIEN, 2013), enquanto elementos do conhecimento. A dimensão relacional, importante para o conhecimento (TRIERVEILER; SELL; PACHECO, 2015), foi explorada nos estudos sobre redes.

Em termos de lacunas de estudos, os resultados da pesquisa mostram a ausência de estudos sobre utilização, armazenamento e reutilização do conhecimento por pequenas empresas, os quais completariam a abordagem do processo da gestão do conhecimento, sugerida por Dalkir (2011). Ainda na dimensão do processo, estudos futuros podem explorar formas de compartilhamento do conhecimento entre indivíduos e grupos e a relação destes com melhora das capacidades coletivas de resolução de problemas no âmbito da pequena empresa, como sugere Julien (2013).

Além disso, pesquisas futuras poderão abranger a gestão do conhecimento em diferentes estágios de desenvolvimento e maturidade de pequenos negócios (EZE et al., 2013; NGUYEN; NEWBY; MACAULAY, 2015). Wong (2005) destaca ainda a importância de incentivos motivacionais e treinamento para a implantação da gestão do conhecimento, que pode ser objeto de pesquisa na pequena empresa.

\section{CONSIDERAÇÕES FINAIS}

Este ensaio teórico teve como objetivo identificar a configuração de estudos sobre gestão do conhecimento em pequenas empresas no Brasil. Foram identificados quarenta estudos publicados. O primeiro estudo foi publicado em 2003. A publicação de forma mais sistemática passou a ocorrer a partir do ano de 2008. Os artigos foram publicados em vinte e sete periódicos, evidenciando a interdisciplinaridade e a multidisciplinaridade deste campo de pesquisa.

As três principais temáticas pesquisadas foram: redes, tecnologia da informação e fontes de informação. Outros estudos dispersos abordaram tópicos como conhecimento em empresas familiares, informação e marketing, práticas de gestão de conhecimento por empresas de moda e gerenciamento de projetos. A pesquisa mostrou que existe ainda um campo de estudos para futuras pesquisas que mostrem, em maior profundidade, como pequenas empresas de diferentes tipos criam, compartilham e armazenam o conhecimento e como este se transforma em inovações ou em aprendizado no contexto dessas empresas.

Ademais, salienta-se que não foram observados estudos sobre utilização, armazenamento e reutilização do conhecimento por pequenas empresas, campo que pode ser explorado em futuras pesquisas. Uma gestão para estudos futuros é a realização de revisões sistemáticas em bases de dados internacionais, que permitam a comparação entre os estudos realizados no Brasil e estudos internacionais, a fim de melhor evidenciar lacunas de estudos.

Esta revisão sistemática demonstrou que a temática da gestão do conhecimento em pequenas empresas apresenta ainda um campo de estudos a ser explorado, importante para compreender a gestão do conhecimento no âmbito da pequena empresa, mais informal e

Perspectivas em Gestão \& Conhecimento, João Pessoa, v. 8, n. 3, p. 209-227, set./dez. 2018. 
flexível. A pesquisa apresenta uma contribuição para pesquisadores na área de pequenas empresas e de gestão de conhecimento, fomentando a reflexão sobre novas possibilidades de pesquisas no campo.

\section{REFERÊNCIAS}

ALMEIDA, D. M.; CORDEIRO, M. B. O uso da informação e da pesquisa de marketing como fator de sucesso na atuação das micro e pequenas empresas, CRCSL \& Você, Florianópolis, 3, 6, p. 45-53, 2003.

ALYA, C. L'organisation fondée sur le savoir: caracteristiques et utilité theorique et pratique. Thèse du Doctorat. Université de Toulouse, 2012.

BARBOZA, R. A. B.; FONSECA, G. A.; RAMALHEIRO, G. C. F. Inovação em MPEs por meio do Serviço Brasileiro de Respostas técnicas. Revista de Administração da Inovação, v. 12, n. 3, p. 330-349, 2015.

BENEDETTI, M. H.; GHOBRIL, N.; ALBARELLO, E. B. Possíveis interações entre conhecimentos externos e internos nos processos de inovações de micro e pequenas empresas. Revista Capital científico-eletrônica, v. 15, n. 3, p. 90-110, 2017.

BERNARDES, D. P. G.; MIRANDA, L. C. Quatro Histórias da utilização de informação econômico financeira nas MPES: lições para futuros empreendedores. Revista de Micro e Pequena Empresa, v. 5, n. 3, p. 84-98, 2011.

BRITO, A. G. C.; ESCRIVÃO FILHO, E. Gestão Estratégica da informação: análise e propostas de melhorias às pequenas empresas do setor de serviços. Revista da Micro e Pequena Empresa da Faculdade Campo Limpo Paulista, v. 3, n. 2, p. 91-105, 2009.

CANCELLIER, E. L. P. L.; SALUM, A. R. C. Monitoramento do ambiente e desempenho em pequenas empresas. Revista de Administração da Inovação, v. 8, n. 3, p. 55-77, 2011.

CANCELLIER, E. L. P.; ALBERTON, A.; SILVA, A. B., MARCON, R. O monitoramento de informações estratégicas do ambiente externo em pequenas empresas. Revista Ibero Americana de Estratégia, v. 8, n. 1, p. 28-51, 2009.

CAPURRO, R. Gestão do conhecimento cético. Perspectivas em Gestão \& Conhecimento, v. 1, n. 1, p.4-14, 2011.

CARLOS FILHO, F. A.; LAGIOIA, V. C. T.; MONTEIRO, J. A. M.; SILVA FILHO, L. L.; ARAUJO, J. G., ARAUJO, J. G. N. Importância e Contribuição do Ativo intangível: percepção dos empreendedores de MPEs sobre o capital intelectual. Organizações em Contexto, v. 10, n. 20, p. 1-27, 2014.

CARVALHO, L. F. Gestão da Informação em micro e pequenas empresas: um estudo do APL do vestuário de Jaraguá, Goiás. Perspectivas em Gestão \& Conhecimento, v. 2, p. 57-72, 2012. 
CASSANDRE, M. P.; ENDRICI, J. M.; VERCESI, C. Gestão por competências nas pequenas empresas do arranjo produtivo local de bonés da cidade de Apucarana (PR): seu entendimento e suas práticas em confronto com as perspectivas teóricas. Revista de Administração da Mackenzie, v. 9, n. 8, p. 1-24, 2008.

DALFOVO, O.; SHARF, E. R.; KRAMBECK, G. A Gestão do conhecimento em ambientes intensivos de conhecimento: as Pequenas Empresas Incubadas de Software. Journal of Information Systems and Technology Management, v. 6, p. 45-60, 2009.

DALKIR, K. Knowledge Management in Theory and Practice. Burlignton: Elsevier, 2011.

DESIDÉRIO, P. H. M.; POPADIUK, S. Redes de inovação aberta e compartilhamento de conhecimento: aplicações em pequenas empresas. Revista de Administração da Inovação, v. 12, n. 2, p. 110-129, 2015.

DESOUZA, K., AWAZU, Y. Knowledge Management at SMEs: five peculiarities. Knowledge Management, v. 10, n. 1, p.32-43, 2006.

DURST, S.; EVARDSSON, I. R. Knowledge Management in SMEs: a literature Review. Journal of Knowledge Management, v. 16, n. 6, p. 879-903, 2012.

EVANGELISTA, P.; ESPOSITO, E., LAURO, V.; RAFFA, M. The Adoption of Knowledge Management Systems in Small Firms. Electronic Journal of Knowledge Management, v. 8, n. 1, p.33-42, 2010.

EZE, U. C.; GOH, G. G. G.; GOH, C.Y.; TAN, T. L . Perspectives of SMEs on Knowledge Sharing. The Journal of Information and Knowledge Management Systems, v. 43, n. 2, 2013, p. 210236.

FEDRIZZI, L. B.; ROLDAN, L. B.; LENZ, G. S.; HANSEN, P. B. Redes horizontais de cooperação contribuindo para o processo de inovação em micro e pequenas empresas brasileiras. Revista de Administração da UNIMEP, v. 6, n. 3, p. 1-23, 2008.

FINARDI, C.; SILVA, E. L.; RADOS, G. J. V. O fluxo da informação em processo de design de moda: uma análise aplicada em pequenas empresas e confecção da grande Florianópolis. Perspectivas em Gestão \& Conhecimento, v. 6, n. 2, p. 204-217, 2016.

GALLON, A. V.; ENSSLIN, S. R.; SILVEIRA, A. Rede de relacionamentos em pequenas empresas de base tecnológica (EBTs) incubadas: um estudo da importância para o desempenho organizacional na percepção de empreendedores. Revista de Gestão de Tecnologia e Sistemas de Informação, v. 6, n. 3, p. 551-572, 2009.

GEIGER, D.; SCHREYÖGG, G. Narratives in knowledge sharing: challenging validity. Journal of Knowledge Management, v. 16, n. 1, p. 97-113, 2012.

GOIS, P. H.; MACHADO, H. P. V. Uma abordagem sobre o papel das redes para pequenas empresas e sobre os efeitos no aprendizado de empreendedores. Revista de Empreendedorismo e Gestão de Pequenas Empresas, v. 1, n. 1, p. 1-21, 2012. 
GRAFTON, W.; SELWYN, C. Using storytelling to elicit tacit knowledge from SMEs. Journal of Knowledge Management, v. 16, n. 6, p. 950-962, 2012.

HOHENDORFF, J. Manual de Produção Científica. Porto Alegre: Penso, 2014.

JORDÃO, R. V. D. Práticas de Gestão do conhecimento na internacionalização de pequenas empresas: um estudo comparativo de casos na indústria de café. BASE-Revista de Administração e Contabilidade da UNISINOS, v. 13, n. 2, p. 171-186, 2016.

JULIEN, P. A. Empreendedorismo Regional e Economia do Conhecimento. São Paulo: Saraiva, 2010.

JULIEN, P. A. O Estado da arte da Pequena e Media Empresa - Fundamentos e Desafios. Florianópolis: Editora da UFSC, 2013.

KRAKAUER, P. V. C.; ALMEIDA, M. I. R. O uso da informação do ambiente no processo de decisão estratégica de empresários brasileiros e americanos de pequenas empresas. BASERevista de Administração e Contabilidade da UNISINOS, v. 13, n.2, p. 111-121, 2016.

KROGH, G. V; ICHIJO, K.; NONAKA, I. Enabling Knowledge Creation. Oxford: University Press, 2000.

LEE, C. S.; WONG, K.Y. Development and validation of knowledge management performance measurement constructs for small and medium enterprises. Journal of Knowledge Management, v. 19, n. 4, p.711-734, 2015.

LÖBLER, M. L., VISENTINI, M. S., LEHNHART, E. R., KEIMECK, A. Elaboração de instrumentos para mensurar os fatores influenciadores na aquisição e na implantação de Sistemas de Informação em micro e pequenas empresas. Revista de Administração, Contabilidade e Economia da FUNDACE, v. 6, n. 1, p. 2-18, 2015.

LUNARDI, G. L.; DOLCI, P. C., MAÇADA, A. C. G. Adoção de tecnologia de informação e seu impacto no desempenho organizacional: um estudo realizado com micro e pequenas empresas. Revista de Administração, v. 45, n. 1, p. 5-17, 2010.

LUNARDI, G. L.; DOLCI, D. B.; Adoção de Tecnologia da informação e sua relação com a gestão de negócios em micro e pequenas empresas. Revista de Administração da UFSM, v. 10, n. 5, p. 929-948, 2017.

MAKAMBE, U. Perspectives on Knowledge Management - A Literature Review. Information and Knowledge Management, 5, 1, p. 88-97, 2015.

MAHELER, A. E D.; VENTURINI, J. C. Criação e disseminação de conhecimento local em pequenas empresas familiares: o caso de cantinas de vinho da região da quarta colônia de imigração italiana, no Rio Grande do Sul. Revista Ibero-Americana de Estratégia, v. 10, n. 2, p. 181-207, 2011.

MARTENS, C. D. P.; BELFORT, A. C.; CARNEIRO, K. D. A.; MARTENS, M. B. Gerenciamento de Projetos em MPEs. Revista Pensamento Contemporâneo em Administração, v. 8, n. 3, p. 151171, 2014.

Perspectivas em Gestão \& Conhecimento, João Pessoa, v. 8, n. 3, p. 209-227, set./dez. 2018. 
MENEZES, C. R. C.; OLAVE, M. E. L. Práticas de Gestão do conhecimento em PMEs de Sergipe. Gestão \& Regionalidade, v. 32, n. 94, p. 4-19, 2016.

MENEZES, C. C., JOHANN, J., VAlEnTIN, P. P., SCOTT, P. Perspectivas em Gestão \& Conhecimento, João Pessoa, v. 7, Número Especial, p. 145-159, 2017.

MORANDI, M. I. I. W. M.; CAMARGO, L. F. R. Revisão sistemática da literatura. In: DRESCH, A.; LACERDA, D. P.; ANTUNES, J. A. V. Design Science Research: método e pesquisa para avanço da ciência e da tecnologia. Porto Alegre: Bookman, 2015.

NETTO, A.V., VALERIO, D.M. Gestão de Pessoas altamente qualificadas em pequenas empresas de base tecnológica. Revista de Administração da Mackenzie, v. 7, n. 3, p. 131-147, 2006.

NGUYEN, T. H. H. Knowledge Management in Small and Medium sized enterprises (SME) in developing country, Vietnam. Tese de Doutorado. Tomas Bata University in Zein. 2011

NGUYEN, T. H.; NEWBY, M.; MACAULAY, M. J. Information Technology Adoption in Small business: Confirmations of a Proposed Framework. Journal of Small Business Management, $\mathrm{v}$. 53, n. 1, p.207-227, 2015.

OLIVEIRA, D. L.; LIPKE, F. A.; SILVA, S. R. F. Capacidades de internet Banking e Desempenho das Pequenas Empresas: o valor do negócio da TI na perspectiva de capacidades externas. BASE Revista de Administração e Contabilidade da UNISINOS, v. 13, n. 4, p. 265-278, out./dez. 2016.

PATTINSON, S., PREECE, D. Communities of practice, Knowledge acquisition and innovation: a case study of Science-based SMEs. Journal of Knowledge Management, v. 18, n. 1, p. 107-120, 2014.

PENROSE, E. A teoria do crescimento da firma. Campinas, SP: Editora Unicamp, 2006.

PRATES, G L. A. inovação Tecnológica através de sistemas de informação em pequenas empresas, sucesso e desafios. Revista Ciência da Administração, Fortaleza, v. 9, n. 1, p. 42-50, 2003.

PRATES, G. A.; OSPINA, M. T. Tecnologia da informação em pequenas empresas: fatores de êxito, restrições e benefícios. Revista de Administração Contemporânea, v. 8, n. 2, p. 9-26, 2004.

RINALDI, A. II sistema dele piccole e media imprese e il "modelo Emilia". Universitàdi Modena e ReggioEmilia. Materiali di discussione. Dipartimento di Economia Politica, 2012, p. 1-22.

ROSSONI, C. F. Balanced Scorecard mediado pela gestão do conhecimento: modelo de uso para micro e pequenas empresas. Revista Micro e Pequena Empresa, v. 4, n. 1, p.20-35, 2010.

SANT'ANNA, P. R.; LONGO, O. C.; BARONE, F. M.; COVA, C. J. G.; OLIVEIRA, F. A. Tecnologia da Informação como ferramenta para análise econômico financeira. Revista de Administração Pública, v. 45, n. 5, p. 1589-1611, 2011.

Perspectivas em Gestão \& Conhecimento, João Pessoa, v. 8, n. 3, p. 209-227, set./dez. 2018. 
SECRETARIA DA MICRO E PEQUENA EMPRESA DA PRESIDÊNCIA DA REPÚBLICA. Tratamento diferenciado às micro e pequenas empresas: Legislação para Estados e Municípios. Brasília, 2013/2014. Disponível em: http://smpe.gov.br/assuntos/cartilha tratamentodiferenciado mpe.pdf.

SOUZA, E. M. O.; OLIVEIRA, D. L.; CUSTÓDIO, E. M. O. Efeitos e características da consumerização de TI nas micro e pequenas empresas: um estudo exploratório. Amazônia, Organizações e Sustentabilidade, v. 6, n. 1, p. 179-195, 2017.

SILVA, W. A.; TEIXEIRA, R. M. Adoção da Tecnologia da Informação pelas MPEs no setor hoteleiro de Sergipe. Revista Brasileira de Pesquisa em Turismo, v. 8, n. 1, p. 59-77, 2014.

SILVEIRA, M. A. P.; AZEVEDO, R. R. A contribuição dos relacionamentos inter organizacionais no processo de aprendizagem em gestão empresarial: um estudo em MPES no Polo Desing Center. Revista da Pequena Empresa da FACCAMP, v. 8, n. 1, p. 68-83, 2014.

SORDI, V.F.; CUNHA, C. J. C.A.; NAKAZAMA, M. K. Perspectivas em Gestão \& Conhecimento, João Pessoa, v. 7, n. 2, p. 160-174, jul./dez. 2017.

SOUZA, P. M.; VASCONCELOS, M. C. R. L.; TAVARES, M. C; CARVALHO, R. B.; GUIMARÃES, E. R. Contribuições dos Sistemas Enterprise Resource Planning para a gestão da informação e do conhecimento: um estudo em uma empresa de pequeno porte na área gráfica. Perspectivas em Gestão \& Conhecimento, v. 3, p. 109-127, 2013.

SOUZA, G. H. S.; LIMA, N. C.; COELHO, J. A. P.; OLIVEIRA, S. V. W.; MILITO, C. N. A influência das redes de cooperação no desenvolvimento de MPEs. Desenvolvimento em Questão, v. 13, n. 31, p. 259-294, 2015.

SOUZA, D. L.; ZAMBALDE, A. L.; OLIVEIRA, N. Estratégia de criação de conhecimento em micro e pequenas empresas por meio de programas de estágio: uma realidade ou um desafio? Revista Empreendedorismo e Gestão de Pequenas Empresas, v. 2, n. 3, p. 33-56, 2013.

SPERAFICO, J.H.; ENGELMAN, R.; GONÇALVES, M.A. Capital intelectual organizacional e inovação em Micro e Pequenas Empresas de Base Tecnológica. RAUnP- Revista Eletrônica do Mestrado Profissional em Administração da Universidade Potiguar, v. 9, n. 1, p. 51-61, 2016.

SUTTER, M. B.; FOERSTER, L.; KRAKAUER, P. V.; PÓLO, E. F.; ALMEIDA, M. I. R. Monitoramento do ambiente na pequena empresa: um estudo de caso sobre o processo em uma empresa do setor imobiliário. Future Studies Research Journal: Trends and Strategies, v. 5, n. 2, p. 187197, 2013.

TAGHIZADEH, S. K.; RAHMAN, S. A.; HOSSAIN, M. M. "Knowledge from customer, for customer or about customer: which triggers innovation capability the most?". Journal of Knowledge Management, v. 22, n. 1, p.162-182, 2018.

TORRÈS, O. Les PMEs. France: Flammarion.1999.

TRIERVEILER, H. J.; SELL, D.; PACHECO, R. C. Importância do conhecimento organizacional para o processo de inovação no modelo de negócios. Navus Revista de Gestão e Tecnologia, v. 5, n. 1, p. 113-126, 2015.

Perspectivas em Gestão \& Conhecimento, João Pessoa, v. 8, n. 3, p. 209-227, set./dez. 2018. 
TSOUKAS, H.; VLADIMIROU, E. What is organizational knowledge? Journal of Management Studies, v. 38, n. 7, p. 973-991, 2001.

TZORTZAKI, A. M.; MIHIOTIS, A. A. Review of Knowledge Management Theory and Future Directions. Knowledge and Process Management, v. 21, n. 1, p.29-41, 2014.

VERSCHOORE, J. R.; KLANOVICS, C.; DURAYSKI, J.; VIEIRA, L. Como a gestão das redes estratégicas regionais afeta os ganhos proporcionados às pequenas empresas associadas. Gestão \& Regionalidade, v. 32, n. 94, p. 131-147, 2016.

WEE, J. C. N.; CHUA, A. Y. K. The peculiarities of knowledge management processes in SMES: the case of Singapore. Journal of Knowledge Management, v. 17, n. 6, p. 958-972, 2013.

WEGNER, D.; BORTOLASO, I. V.; ZANATTO, P. A. F. Redes de pequenas empresas e estratégias de consolidação: evidências do contexto brasileiro. Revista Brasileira de Gestão de Negócios, v. 18, n. 62, p. 525-544, 2016.

WENGER, D.; MISOCSKY, M.C. Avaliação de Desempenho de redes de pequenas empresas: contribuições da abordagem da produção do sentido. Organização \& Sociedade, v. 17, n. 53, p. 345-361, 2010.

WONG, K. Y. Critical Success Factors for Implementing Knowledge Management in Small and Medium Enterprises. Industrial Management \& Data Systems, v. 105, n. 3, p.261-279, 2005.

ZAHN, E.; FOSCHIANI, S.; TILEBEIN, M. Nachhaltige Wettbewerbsvorteiledurch Wissensmanagement. In: KRALLMAN, $\mathrm{H}$. Wett bewerbsvorteile durchWissensmanagementMethodik und Andwendungen des Knowledge Management. Stuttgart: Schäffer-Poeschel Verlag, 2000.

ZAMPIERI, M.A., TAKAHASHI, A.R.W. Aprendizagem e competências empreendedoras: estudo de casos de MPE do setor educacional. Revista Gestão Organizacional, v. 6, n. 4, p. 3-18, 2013. 